\title{
Organ-dependent oxylipin signature in leaves and roots of salinized tomato plants (Solanum lycopersicum)
}

\author{
Michel Edmond Ghanem ${ }^{\mathrm{a}, \mathrm{c}}$, Mohamed Ali Ghars ${ }^{\mathrm{b}}$, Patrick Frettinger ${ }^{\mathrm{b}}$, Francisco Pérez-Alfocea ${ }^{\mathrm{c}}$, \\ Stanley Lutts ${ }^{\mathrm{a}}$, Jean-Paul Wathelet ${ }^{\mathrm{d}}$, Patrick du Jardin ${ }^{\mathrm{b}}$, Marie-Laure Fauconnier ${ }^{\mathrm{b}, *}$

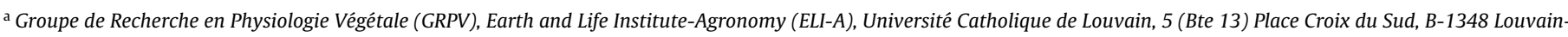 \\ La-Neuve, Belgium \\ b Plant Biology Unit, Gembloux Agro-Bio Tech, University of Liège, Passage des Déportés 2, B-5030 Gembloux, Belgium

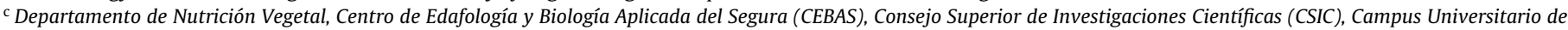 \\ Espinardo, 30100 Murcia, Spain \\ d General and Organic Chemistry Unit, Gembloux Agro-Bio Tech, University of Liège, Passage des Déportés 2, B-5030 Gembloux, Belgium
}

\section{A R T I C L E I N F O}

\section{Article history:}

Received 24 December 2011

Received in revised form 18 March 2012

Accepted 21 March 2012

\section{Keywords:}

Lipoxygenase

Oxylipin

Salt stress

Tomato (Solanum lycopersicum L.)

\begin{abstract}
A B S T R A C T
Oxylipins have been extensively studied in plant defense mechanisms or as signal molecules. Depending on the stress origin (e.g. wounding, insect, pathogen), and also on the plant species or organ, a specific oxylipin signature can be generated. Salt stress is frequently associated with secondary stress such as oxidative damage. Little is known about the damage caused to lipids under salt stress conditions, especially with respect to oxylipins. In order to determine if an organ-specific oxylipin signature could be observed during salt stress, tomato (Solanum lycopersicum cv. Money Maker) plants were submitted to salt stress $(100 \mathrm{mM}$ of $\mathrm{NaCl}$ ) for a 30 -d period. A complete oxylipin profiling and LOX related-gene expression measurement were achieved in leaves and roots. As expected, salt stress provoked premature senescence in leaves, as revealed by a decrease in photosystem II efficiency $\left(F_{\mathrm{v}} / F_{\mathrm{m}}\right.$ ratio $)$ and sodium accumulation in leaves. In roots, a significant decrease in several oxylipins (9- and 13-hydro(pero)xy linole(n)ic acids, keto and divinyl ether derivatives) was initiated at day 5 and intensified at day 21 after salt treatment, whereas jasmonic acid content increased. In leaves, the main changes in oxylipins were observed later (at day 30), with an increase in some 9- and 13-hydro(pero)xy linole(n)ic acids and a decrease in some keto-derivatives and in jasmonic acid. Oxylipin enantiomeric characterization revealed that almost all compounds were formed enzymatically, and therefore a massive auto-oxidation of lipids that can be encountered in abscission processes can be excluded here.
\end{abstract}

(c) 2012 Elsevier GmbH. All rights reserved.

\section{Introduction}

Salinity is an increasing problem around the world, either due to salts naturally present in the soil, irrigation practices or the clearing of land for dryland agriculture (Munns, 2011). More than 800 mil-

Abbreviations: aqu, aquaporin gene; AOC, allene oxide cyclase; AOS, allene oxide synthase; CA, colneleic acid; Cn A, colnelenic acid; DES, divinyl ether synthase; dehy, dehydrin gene; 9-HOD, 9-hydroxy linoleic acid; 13-HOD, 13-hydroxy linoleic acid; 9-HOT, 9-hydroxy linolenic acid; 13-HOT, 13-hydroxy linolenic acid; HPL, hydroperoxide lyase; 9-HPOD, 9-hydroperoxy linoleic acid; 13-HPOD, 13-hydroperoxy linoleic acid; 9-HPOT, 9-hydroperoxy linolenic acid; 13-HPOT, 13-hydroperoxy linolenic acid; JA, jasmonic acid; 9-KOD, 9-keto linoleic acid; 13-KOD, 13-keto linoleic acid; 9-KOT, 9-keto linolenic acid; 13-KOT, 13-keto linolenic acid; lea, late embryogenis abundant gene; LOX, lipoxygenase; MDA, malondialdehyde; OPDA, oxo-phytodienoic acid; OPR, oxo-phytodienoate reductase.

* Corresponding author. Tel.: +32 816224 60; fax: +32 81600727.

E-mail address: marie-laure.fauconnier@ulg.ac.be (M.-L. Fauconnier). lion hectares of land worldwide are affected by salinity (Qadir et al., 2007), and improving crop salt tolerance is therefore a key goal for global agriculture. Salt decreases crop yields by reducing growth and inducing leaf senescence due both to an osmotic stress (plant water deficit) and an ionic stress provoked by nutritional imbalances and the accumulation of toxic ions such as sodium (Munns and Tester, 2008).

Salinity affects plant productivity by reducing the photosynthetic area through the inhibition of cell division and cell expansion rates during leaf growth, and by affecting developmental programs regulating leaf emergence, production of lateral primordia, and the formation of reproductive organs (summarized in Munns, 2002).

Plant productivity under salt stress conditions depends on photosynthetic processes in the leaves, which are strongly dependent on an adequate supply of water, mineral nutrients, small organic molecules and hormones (Pérez-Alfocea et al., 2010). Several of these compounds are either synthesized in the roots (i.e. hormones, amino acids) or taken up (i.e. water and mineral nutrients) by the 
roots and must be transported to the shoot to enable normal leaf functioning (see Ghanem et al., 2011 for a review).

As a consequence of the primary effects of salt stress, secondary stresses such as oxidative damage often occur. The role of enzymatic and non-enzymatic mechanisms developed by plants to reduce such damage has been extensively studied (Zhu, 2001). Surprisingly, little is known about the damage caused to lipids under salt stress conditions, and more precisely about oxylipins despite their involvement in the control of membrane properties and their potential role as signal molecules (Mosblech et al., 2010).

Oxylipins are a class of lipid metabolites that derive from oxidation of polyunsaturated fatty acids, and in plants are mainly linoleic acid (18:2), $\alpha$-linolenic acid (18:3) or roughanic acid (16:3). The first step of the oxylipin pathway results in the formation of fatty acid hydroperoxides (HPO). The process can occur by chemical auto-oxidation or can be catalyzed by two distinct enzymatic reactions: the lipoxygenase (LOX) or the $\alpha$-dioxygenase (Mosblech et al., 2010). In higher plants, LOX catalyses the dioxygenation of polyunsaturated fatty acids in a regional and stereo-specific way, leading to the formation $13 S$ hydroperoxy derivatives (13-LOX) or 9S hydroperoxy derivatives (9-LOX) ((Mosblech et al., 2009). The HPO can be further converted via several diverging pathways into oxygenated compounds presenting various chemical structures (volatile aldehydes, oxo-derivatives, hydroxy-derivatives, ketoderivatives, divinyl ethers and cyclopentenones) (Mueller et al., 2008; Mosblech et al., 2010). Hydroperoxide lyase (HPL) cleaves HPO into a volatile aldehyde and a $\omega$-oxo fatty acid, while divinyl ether synthase (DES) forms divinyl ethers such as colnele(n)ic acids. Hydroxy fatty acids (HO) can be formed by both reductase and peroxygenase by distinct mechanisms; keto-derivatives result from the action of the LOX itself on HPO. Allene oxide synthase (AOS) catalyses the formation of an unstable allene oxide that can be non-enzymatically transformed into cyclopentenone or into $\alpha$ or $\beta$-ketols. The allene oxide formed from 13-hydroperoxide of linolenic acid (13-HPOT) can be transformed by allene oxide cyclase (AOC) into the biologically active 12-oxo phytodienoic acid (OPDA), and further converted by several enzymatic steps into the phytohormone jasmonic acid (JA). Oxylipins can be found, in plants, as free compounds or esterified with other molecules such as phospholipids or galactolipids (Andreou and Feussner, 2009; Mosblech et al., 2009).

Oxylipins assume key functions in plant defense mechanisms (Blée, 2002) or as signal molecules (Mosblech et al., 2010). JA, and more particularly its derivatives (methyl ester derivative, conjugate of JA and isoleucine) and precursor (OPDA), have been described for their important signaling roles in the development process or defense mechanisms under (a)biotic stress (Browse, 2009; Seltmann et al., 2010).

It has been shown that, depending on the stress origin (e.g. wounding, insect, pathogen agent), and also on the plant species or organ, a specific oxylipin signature may be generated (Blée, 2002; Fauconnier et al., 2008; Gosset et al., 2009).

In the context of salt stress, the role of JA as a signal molecule has also been highlighted, and an increase of lipid peroxidation or LOX activity has been described (Ben-Hayyim et al., 2001; Molina et al., 2002; Abdala et al., 2003; Pedranzani et al., 2003; Elkahoui et al., 2005; Delaplace et al., 2009). However, exhaustive data concerning oxylipin profiling and/or kinetic parameters in salt-stressed plants are still lacking.

Previous studies have addressed how phytohormone concentrations may be affected by salinity in tomato in relation to leaf senescence and biomass partitioning (Ghanem et al., 2008; Albacete et al., 2008, 2009), but have also revealed an increase in malondialdehyde (MDA) concentration 15 days after salt stress application (Ghanem et al., 2008). MDA is a marker of lipid oxidation frequently used to assess oxidative damage to lipids in biological samples. However, it does not allow for a distinction between enzymatic and non-enzymatic processes, nor for the accurate evaluation of damage to individual lipids that can be achieved by oxylipin profiling.

The present study was conducted to address the following questions:

- Is there a specific organ-dependent (root vs. leaves) oxylipin signature under salt stress conditions in tomato?

- Does the oxylipin signature differ between early and late phases of salt stress response?

- Are the main oxylipins formed enzymatically through the LOX pathway or by a non-enzymatic oxidation process, and how is this related to the observed physiological damage?

Accordingly, lipid peroxidation in both tomato roots and leaves submitted to salt stress $(100 \mathrm{mM}$ of $\mathrm{NaCl})$ for a period of 30 days was assessed by oxylipin profiling (including enantiomeric characterization) in relation to the study of the expression of LOX pathway genes. Classical physiological and biochemical parameters, such as the efficiency of the photosystem II in leaves, and $\mathrm{Na}^{+}$and $\mathrm{K}^{+}$concentrations, were quantified, and the expression of genes known to be regulated in a salt stress context were also analyzed [dehydrin (dehy), aquaporin (aqu) and late embryogenis abundant (lea)].

\section{Materials and methods}

\section{Plant material and culture conditions}

Seeds of tomato Solanum lycopersicum cv. Money Maker were sown and seedlings allowed to grow in a germination chamber in trays filled with vermiculite moistened regularly with a half-strength modified Hoagland nutrient solution. The nutrient solution contained the following chemicals (in $\mathrm{mM}$ ): $5 \mathrm{KNO}_{3}, 1$ $\mathrm{NH}_{4} \mathrm{H}_{2} \mathrm{PO}_{4}, 0.5 \mathrm{MgSO}_{4}, 5.5 \mathrm{Ca}\left(\mathrm{NO}_{3}\right)_{2}$ and (in $\left.\mathrm{lM}\right) 25 \mathrm{KCl}, 10 \mathrm{H}_{3} \mathrm{BO}_{3}$, $1 \mathrm{MnSO}_{4}, 1 \mathrm{ZnSO}_{4}, 0.25 \mathrm{CuSO}_{4}, 10 \mathrm{Na}_{2} \mathrm{MoO}_{4}$, and $1.87 \mathrm{mgl}^{-1} \mathrm{Fe}-$ EDDHA. Fourteen days after sowing, seedlings were transferred into a growth chamber and fixed on polyvinyl chloride plates floating on aerated half-strength modified Hoagland nutrient solution. Solutions were refilled every 2 days and renewed every week.

Plants were grown in a growth chamber under a $16 \mathrm{~h}$ daylight period. The air temperature ranged from $25^{\circ} \mathrm{C}$ to $28^{\circ} \mathrm{C}$ during the day and from $17^{\circ} \mathrm{C}$ to $18^{\circ} \mathrm{C}$ during the night. Relative humidity was maintained at $70 \pm 5 \%$ during the night and at $50 \pm 5 \%$ during the day. Light intensity at the top of the canopy was $\sim 245 \mu \mathrm{mol} \mathrm{m}^{-2} \mathrm{~s}^{-1}$ [photosynthetic photon flux density]. After 5 days of acclimatization in control conditions (18 days after sowing), the seedlings were exposed to 0 (control) or $100 \mathrm{mM} \mathrm{NaCl}$ (salt) added to the nutrient solution for 30 days. Three replicates with eight plants per replicate and salt treatment were used in this study to measure different parameters. An actively growing leaf, present when salt stress was applied (leaf 4), and root were harvested for different analyses at $0,5,21$ and 30 days of salt treatment.

A total of 120 plants were evaluated in each experiment. Treatments were randomly distributed across available tanks within the growth chamber, and re-randomized for each experiment to avoid positional effects on growth. Although the experiment was repeated three times with similar results, the data set presented for oxylipin profiling determination data corresponds to Experiment \#1. Indeed, similar profiles were obtained for the three independent biological repetitions, in spite of the attention devoted to plant culture and analytical procedures, and the absolute value slightly differed from one repetition to another, increasing standard deviation and consequently making data interpretation more difficult. 


\section{Oxylipin analysis}

Free oxylipin was extracted and analyzed according to Göbel et al. (2002) with a three step HPLC procedure using internal standards for quantification. Extraction of free oxylipins: $(6 Z, 9 Z, 11 E$, 13S)-13-hydroxy-6,9,11-octadecatrienoic acid (Cayman Chemical, East Ellsworth, MI, USA) was used as the internal standard, and $2.0 \mathrm{~g}$ of frozen material was added to $20 \mathrm{~mL}$ of extraction medium [isohexane/2-propanol, 3/2 (v/v) with 0.0025\% (w/v) BHT]. After homogenization, the extract was centrifuged at $1300 \times \mathrm{g}$ at $4{ }^{\circ} \mathrm{C}$ for $10 \mathrm{~min}$. The clear upper phase was collected and a $6.7 \%(\mathrm{w} / \mathrm{v})$ solution of potassium sulfate was added to reach a volume of $32.5 \mathrm{~mL}$. After vigorous shaking, the extract was centrifuged at $1300 \times g$ at $4{ }^{\circ} \mathrm{C}$ for $10 \mathrm{~min}$. The upper hexane-rich layer containing the oxylipin fatty acid derivatives was collected and used for further HPLC analysis.

\section{Free oxylipin HPLC analysis}

The first step of free oxylipin analysis, performed on the reverse phase column, allowed group separation. Each separated fraction was collected and then injected onto a straight-phase column, allowing for the individual separation of oxylipins. Reverse-phase HPLC analysis was performed on an EC250/2 Nucleosil 120-5 C18 column $(250 \mathrm{~mm} \times 2.1 \mathrm{~mm}, 5 \mu \mathrm{m}$ particle size; Macherey \& Nagel, Easton, PA, USA) using the following binary gradient system: solvent $A$ (methanol:water:acetic acid (75:15:0.1, v/v) and solvent $B$ (methanol:water:acetic acid (100:0:0.1, v/v), with the following gradient program: $20 \%$ solvent B for $10 \mathrm{~min}$, followed by a linear increase of solvent B up to $40 \%$ within $28 \mathrm{~min}$, a linear increase of solvent B up to $100 \%$ within $30 \mathrm{~min}$ and held for $15 \mathrm{~min}$, a linear decrease by up to $20 \%$ of solvent B within 5 min and, finally, by an isocratic post-run at $15 \%$ of solvent $B$ for $6 \mathrm{~min}$. The flow rate was $0.18 \mathrm{~mL} \mathrm{~min}^{-1}$ up to $30 \mathrm{~min}$ and increased linearly to $0.36 \mathrm{~mL} \mathrm{~min}^{-1}$ within $35 \mathrm{~min}$, held for $10 \mathrm{~min}$, followed by a linear decrease to $0.18 \mathrm{~mL} \mathrm{~min}^{-1}$ within $50 \mathrm{~min}$ and a post-run for $6 \mathrm{~min}$. The injection volume was $80 \mu \mathrm{L}$. Straight-phase HPLC was performed on a Zorbax Rx-SIL column $(150 \mathrm{~mm} \times 2.1 \mathrm{~mm}, 5 \mu \mathrm{m}$ particle size, Agilent, Palo Alto, CA, USA) with $n$-hexane/2-propanol/acetic acid $(100: 1: 0.1, \mathrm{v} / \mathrm{v} / \mathrm{v})$ as a solvent system at a flow rate of $0.2 \mathrm{~mL} \mathrm{~min}^{-1}$. The injection volume was $25 \mu \mathrm{L}$ and the absorbance was recorded at $234 \mathrm{~nm}$. The enantiomeric composition of the hydroxy fatty acids was analyzed by chiral-phase HPLC on a Chiral OD-H column (150 mm $\times 2.1 \mathrm{~mm}, 5 \mu \mathrm{m}$ particle size; Baker, Phillipsburg, NJ, USA) with $n$-hexane/2-propanol/acetic acid (100:5:0.1, v/v/v) as a solvent system at a flow rate of $0.1 \mathrm{~mL} \mathrm{~min}^{-1}$. The injection volume was $10 \mu \mathrm{L}$. Free jasmonic acid (JA) and OPDA contents were determined using the method according to Göbel et al. (2002). Briefly, JA and OPDA were collected during the straight phase HPLC step, derivatized using pentafluorobenzylbromide and analyzed by GC-MS in single ion monitoring mode with ammoniac as chemical ionization gas. The results were expressed in terms of $\mathrm{nmol} \mathrm{g}^{-1} \mathrm{FW}$. The analysis was performed in triplicate on three independent biological assays. Results presented in the figure are the mean \pm standard deviation for biological repetition 1 .

\section{Ribonucleic acid (RNA) extraction, cDNA macroarray preparation and hybridization}

RNA extractions from the control and stressed tomato leaves and roots were performed following the procedure of Wang et al. (2000). RNA quality was estimated on 1\% agarose gel. RNA was quantified using Nanodrop ND-1000. cDNA was synthesized from $400 \mathrm{ng}$ of total RNA using RevertAid H Minus First Strand cDNA Synthesis Kit (Fermentas). To perform expression analysis, specific primer sets of $S$. lycopersicum were designed for Lox, Opr, AOC, AOS,
DES, HPL, dehy, aqu, lea and 18S (housekeeping gene). Table 1 indicates the genes selected in this work, the corresponding gene bank accessions and the primers used for generating the PCR products. Reverse transcription polymerase chain reaction (RT-PCR) was performed on a Bio Rad's thermocycler. From each PCR, PCR products were loaded onto a $1 \%$ agarose gel and the amplification products corresponding to the genes of interest were isolated from the agarose gel using a protocol according to Sambrook and Russell (2006). The ligation of the cDNA genes in a pCR4-TOPO vector was performed with a TOPO TA Cloning Kit for Sequencing (Invitrogen). These plasmids were amplified into Escherichia coli cells and finally isolated with GeneJet Plasmid Miniprep kit (Fermentas). cDNA clones of interest were amplified with a specific primer (M13F and M13R) and immobilized on nylon membranes (HybondXL from Amersham Biosciences). RNA was isolated from a selected tissue, reverse-transcribed to cDNA in the presence of radioactive nucleotides ( $\left.{ }^{32} \mathrm{P}-\mathrm{dCTP}\right)$, and then incubated with the prepared nylon membranes to allow the labeled cDNA to bind to its complement on the array. After being exposed to a phosphorImager screen and measured by a STORM PhosphorImager, a membrane image file was produced and the signal was analyzed using the ImageQuant (Amersham Bioscience) analysis software.

\section{Ion $\left(\mathrm{Na}^{+}\right.$and $\left.\mathrm{K}^{+}\right)$quantification}

Leaf and root tissues were weighed to determine their fresh weight (FW), then oven-dried at $70^{\circ} \mathrm{C}$ for $48 \mathrm{~h}$ and $50 \mathrm{mg}$ dry weight (DW) was digested in $35 \%(\mathrm{v} / \mathrm{v}) \mathrm{HNO}_{3}$ at $80^{\circ} \mathrm{C}$. Ions were dissolved in $0.1 \mathrm{M} \mathrm{HCl}$ and concentrations determined (in triplicate for each sample) using an inductively coupled argon plasma emission spectrophotometer (YJ48; Jobin Yvon, Edison, NJ, USA) calibrated with certified standard solutions.

The results were expressed in terms of $\mathrm{mM}$ as they took into account the physiological water status of leaves and roots.

\section{Chlorophyll fluorescence}

Modulated chlorophyll fluorescence was measured in darkadapted (30 min) leaves using a pulse-modulated chlorophyll fluorometer FMS-2 (Hansatech Instruments Ltd., Norfolk, UK) as reported previously (Ghanem et al., 2008). An excitation source intensity of $3000 \mu \mathrm{mol} \mathrm{m}{ }^{-2} \mathrm{~s}^{-1}$ was used and $F_{0}$ was measured in the presence of a far-red light background to favor rapid oxidation of intersystem electron carriers. The maximal fluorescence intensities in the dark-adapted state were measured after a $0.8 \mathrm{~s}$ saturating pulse. The maximum quantum yield of open photosystem II (PSII) $\left(F_{\mathrm{v}} / F_{\mathrm{m}}\right)$ was calculated as $\left(F_{\mathrm{m}}-F_{0}\right) / F_{\mathrm{m}}$ as reported previously (Ghanem et al., 2008).

\section{Statistical analysis}

Data were subjected to an analysis of variance (ANOVA II) using the SAS software (SAS System for Windows, version 8.02), with mean discrimination achieved using the Student-Newman-Keuls test at the $5 \%$ level.

\section{Results}

\section{Chlorophyll fluorescence and sodium and potassium contents}

The phenotype of salinized tomato plants was similar to what was observed in our previous studies (Ghanem et al., 2008). Salinity decreased both the total number of leaves and the growth of individual leaves and the fresh and dry weight of shoots. Shoot growth was more affected than root growth (data not shown). 
Table 1

Genes and oligonucleotide specific primers of Solanum lycopersicum used in reverse transcription polymerase chain reaction (RT-PCR).

\begin{tabular}{|c|c|c|c|c|}
\hline Primer type & $\begin{array}{l}\text { Oligonucleotide sequences (forward } \\
\text { primer) }\end{array}$ & $\begin{array}{l}\text { Oligonucleotide sequences (reverse } \\
\text { primer) }\end{array}$ & $\begin{array}{l}\text { GenBank accession } \\
\text { number }\end{array}$ & Gene \\
\hline Lox A & 5'-GCCTAATCATGGCAAGGTCC-3' & 5'-CCTATCCCACGCCTCGCGC-3' & U09026.1 & $\begin{array}{l}\text { Lycopersicon esculentum lipoxygenase (Lox } \\
\text { A) mRNA, complete cds }\end{array}$ \\
\hline Lox B & 5'-GAGGCAGGACAGGCCGCGAACC-3' & 5'GCCTTAAACGCAGGGAGGAGCG-3' & U09025.1 & $\begin{array}{l}\text { Lycopersicon esculentum lipoxygenase (Lox } \\
\text { B) mRNA, complete cds }\end{array}$ \\
\hline Lox D & 5'-GCAAAGGGCTACTTGTGAAG-3' & 5'-GTGAACTTGGACCAGTCTGGG-3' & U37840.1 & $\begin{array}{l}\text { Lycopersicon esculentum lipoxygenase (Lox } \\
\text { D) mRNA, complete cds }\end{array}$ \\
\hline Lox E & 5'-GAATCAAGTTGCCTCAGGGGC-3' & 5'-CTGACATCAGGCATCAGGATG-3' & AY008278.1 & $\begin{array}{l}\text { Lycopersicon esculentum lipoxygenase } \\
\text { mRNA, complete cds }\end{array}$ \\
\hline Opr1 & 5'-CTGCACAGACAGAGGACTAACACC-3' & 5'-ATGCGCAAATGGGGATATCC-3' & AJ242551.1 & $\begin{array}{l}\text { Lycopersicon esculentum mRNA for } \\
\text { 12-oxophytodienoate reductase (Opr gene) }\end{array}$ \\
\hline Opr2 & 5'-CGATCGGCATTGGCTGGTCC-3' & 5'-CCAGGGCAAGACGACAACG-3' & AJ278331.1 & $\begin{array}{l}\text { Lycopersicon esculentum mRNA for putative } \\
\text { 12-oxophytodienoate reductase } 2 \text { (Opr2 } \\
\text { gene) }\end{array}$ \\
\hline Opr3 & 5'-CGAGCAGAGAGCGACGGCCG-3' & 5'-GGCTTCTCAGTGGATGATATTGG-3' & AJ278332.1 & $\begin{array}{l}\text { Lycopersicon esculentum mRNA for } \\
\text { 12-oxophytodienoate reductase } 3 \text { (Opr3 } \\
\text { gene) }\end{array}$ \\
\hline AOS & 5'-CGACGGCAAGAGTTTTCCGG-3' & 5'-CGCAGCTTGATCACTGCCG-3' & AF230371.1 & $\begin{array}{l}\text { Lycopersicon esculentum allene oxide } \\
\text { synthase }(A O S) \text { mRNA, complete cds }\end{array}$ \\
\hline $\mathrm{AOC}$ & 5'-GCCTCTGCTGCTCTTAGAACC-3' & 5'-CGAAGATAAGCAGGGCTTCC-3' & AF384374.1 & $\begin{array}{l}\text { Lycopersicon esculentum allene oxide } \\
\text { cyclase }(A O C) \text { mRNA, complete cds }\end{array}$ \\
\hline HPL & 5'-GGTTACTCTGCCCGTCCGTTCG-3' & 5'-GCTCTTTAAGTAGTGTAGGCACC-3' & AF230372.1 & $\begin{array}{l}\text { Lycopersicon esculentum fatty acid } \\
\text { hydroperoxide lyase }(H P L) \text { mRNA, } \\
\text { complete cds }\end{array}$ \\
\hline DES & 5'-CGGTGGTTATCGTCCCGTCG-3' & 5'-GCCAAGAACTGTATCAGACG-3' & AF317515.1 & $\begin{array}{l}\text { Lycopersicon esculentum divinyl ether } \\
\text { synthase (DES) mRNA, complete cds }\end{array}$ \\
\hline Dehy1 & 5'-GCACGGGTACTGGCGGTATG-3' & 5'-GCATCCCAGGGATCTTGTCC-3' & U26423.1 & $\begin{array}{l}\text { Lycopersicon esculentum dehydrin TAS14 } \\
\text { (tas14) gene, complete cds }\end{array}$ \\
\hline Dehy2 & 5'-GCAGCTCTAGTAGCTCCAGTG-3' & 5'-CCTCTTCAGCCTTTGAGTG-3' & BE431649.1 & $\begin{array}{l}\text { EST336465 tomato breaker fruit, TIGR } \\
\text { Solanum lycopersicum cDNA clone } \\
\text { cLEG30G1 similar to Lycopersicon chilense } \\
\text { DUN dehydrin (pLC3015), mRNA sequence }\end{array}$ \\
\hline Dehy3 & 5'-CGTGGAAGCTACTGATCGTG-3' & 5'-CGATTCTTCGTTGTGATCAC-3' & BF097038.1 & $\begin{array}{l}\text { EST361002 tomato nutrient deficient roots } \\
\text { Solanum lycopersicum cDNA clone } \\
\text { cLEW19K23 5-sequence similar to } \\
\text { Lycopersicon chilense DUN dehydrin, mRNA } \\
\text { sequence }\end{array}$ \\
\hline Aqu1 & 5'-GCTCCACTGTTGCTTGCCTCC-3' & 5'-GAAGTGGTGTGTGGCATCC-3' & AY731066.1 & $\begin{array}{l}\text { Lycopersicon esculentum putative } \\
\text { aquaporin TIP-type mRNA, partial cds }\end{array}$ \\
\hline Aqu2 & 5'-GGCACTGCTTTGGGTGC-3' & 5'-GGCCTTAATAGCTGCAGC-3' & AY725511.1 & $\begin{array}{l}\text { Lycopersicon esculentum putative } \\
\text { aquaporin PIP-type mRNA, partial cds }\end{array}$ \\
\hline lea4 & 5'-CGGTTTCGACGGCCTTGC-3' & 5'-GGTGATGTTGCCAATGAC-3' & Z46654.1 & $\begin{array}{l}\text { L. esculentum Marmande mRNA for late } \\
\text { embryogenesis-like protein }\end{array}$ \\
\hline lea5 & 5'-CCGGAGGCTGACATCACG-3' & 5'-GCTTGATCTCGCCGCTATGTG-3' & U77719.1 & $\begin{array}{l}\text { Lycopersicon esculentum } \\
\text { ethylene-responsive late } \\
\text { embryogenesis-like protein (ER5) mRNA, } \\
\text { complete cds }\end{array}$ \\
\hline $18 \mathrm{~S}$ & 5'-GTAGTCATATGCTTGTCTC-3' & 5'-GGCTGCTGGCACCAGACTTGC-3' & X51576.1 & Tomato 17S rRNA gene \\
\hline
\end{tabular}

Consequently, salinization increased the root/shoot ratio up to twofold compared to control plants (data not shown).

Evolution of chlorophyll fluorescence and senescence-related parameters [as measured by the maximum quantum efficiency of PSII $\left(F_{\mathrm{v}} / F_{\mathrm{m}}\right)$ ] during salt stress is shown in Fig. 1. In leaf 4 of the control plants, the maximum quantum efficiency of PSII $\left(F_{\mathrm{v}} / F_{\mathrm{m}}\right)$ was more or less constant during the growing period, whereas in salt-treated plants, these values sharply decreased below those of control plants at two weeks (day 15) after salinization.

Sodium was accumulated at a level of up to $60 \mathrm{mM}$ during the first 5 days of salt treatment. A strong increase (until $150 \mathrm{mM}$ ) occurred at the second harvest time (21 days) (Fig. 2). Salinity induced a strong reduction in $\mathrm{K}^{+}$content in leaf 4 at the fifth day of salt treatment (Fig. 2). This decrease continued until the end of the third harvest period (30 days).

\section{Oxylipin analysis}

Overall, it was noted that oxylipin contents were higher in roots (Figs. 3 and 4) compared to leaves (Figs. 5 and 6), which can be partially explained by the respective water contents of the below

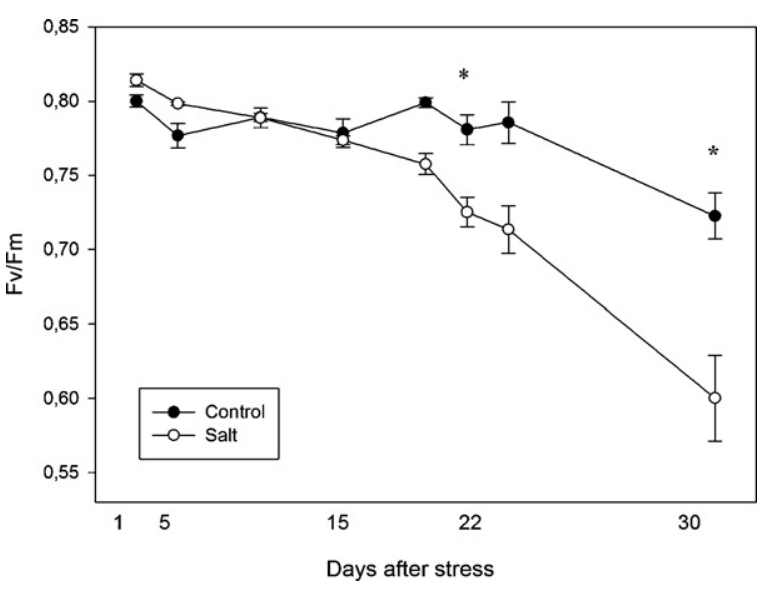

Fig. 1. Evolution of maximum photochemical efficiency $\left(F_{\mathrm{v}} / F_{\mathrm{m}}\right)$ in leaves 4 of tomato plants grown for 30 days on half-strength Hoagland medium in the absence (filled circles) or in the presence of $100 \mathrm{mM} \mathrm{NaCl}$ (open circles). Data are means of 8 plants \pm SE. Asterisks indicate significant differences between control and salinized leaves according to Student-Newman-Keuls test at $P<0.05$. 

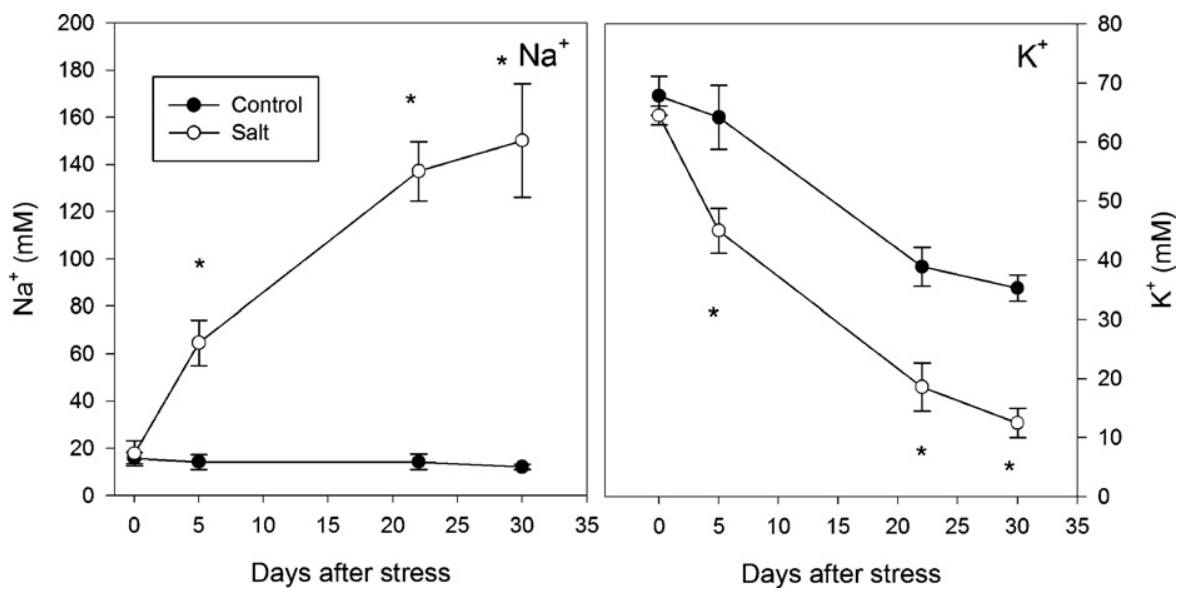

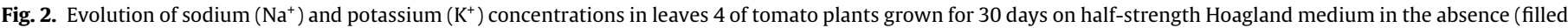

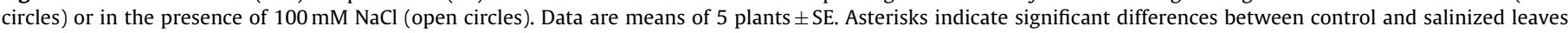
according to Student-Newman-Keuls test at $P<0.05$.

ground and above ground organs. The major oxylipins found in roots (Fig. 3) were, in decreasing order: 9-hydroxy linoleic acid (9HOD, 9-hydroperoxy linoleic acid (9-HPOD), 13-hydroxy linoleic acid (13-HOD) and 9-hydroxy linolenic acid (9-HOT); while in leaves (Fig. 5) four major oxylipins were present at nearly the same range of concentrations: 13-HOD, 13-hydroxy linolenic acid (13-HOT), 9-HOD and 9-HOT. In addition to hydroxy fatty acids (HOD/T) and hydroperoxy fatty acids (HPOD/T), keto-derivatives $(\mathrm{KOD} / \mathrm{T})$, jasmonic acid and its precursor, OPDA, were encountered both in leaves and roots while the divinyl ethers (colneleic acid (CA) and colnelenic acid ( $\mathrm{Cn} A)$ ) were detected only in roots (Figs. 4 and 6). In roots (Figs. 3 and 4), the oxylipin derived from linoleic acid (D) constituted the major class; both $\mathrm{D}$ and $\mathrm{T}$ derivatives were found in leaves (Figs. 5 and 6). Depending on the LOX isoforms, 9-, 13- or 9- and 13-oxylipins can be formed. In roots, 9-derivatives (9-HOD, 9-HPOD, 9-HOT, 9-hydroperoxy linolenic acid (9-HPOT), 9-keto linoleic acid (9-KOD), 9-keto linolenic acid (9-KOT)) were much more abundant than the corresponding 13derivatives (Figs. 3 and 4); in leaves (Figs. 5 and 6), both 9- and 13-oxylipins were present.

During development of tomato plants in control conditions, a significant increase was observed in the roots from day 0 to day 5 for 13-keto linolenic acid (13-KOT), and for several oxylipins (13-hydroperoxy linoleic acid (13-HPOD), 13-HPOT, 9-HPOD, 9HPOT, 9HOT, 13-keto linoleic acid (13-KOD)) from day 5 to day 21 , followed by a significant decrease from day 21 to day 30 for 13-HPOD, 13-HPOT, 9-HPOD, 9-HPOT, 9-HOT, 13-KOD and 9-KOD (Figs. 3 and 4). In leaves (Figs. 5 and 6), the following statistically significant modifications were observed during development of control plants: from day 0 to day 5, JA decreased while OPDA increased; from day 5 to day 21, there was a decrease for 13-HPOD, 9-HPOD and 9-HOD; and from day 21 to day 30, a decrease was found for 13-HOD and an increase for 13-KOT and JA.

After salinization, the oxylipin pattern of tomato plants was affected in the following way when comparing plants of the same harvest period. In roots (Figs. 3 and 4 ), after 5 days of salt treatment no significant modification was noted while, after 21 days of salinization, a decrease was observed for 13-HOD, 13-HPOD, 13HOT, 13-HPOT, 9-HPOD, 9-HPOT, 9-HOD, 9-HOT, 9-KOD, CA and an increase for JA. After 30 days of treatment, the only difference between control and treated plants consisted in a 13-HOD, 9-HPOD and 9-HPOT decrease. In leaves (Figs. 5 and 6), after 5 days of treatment, 13-HPOT and 13-KOD increased significantly; after 21 days, 9-HPOD, 9-HPOT, 9-HOT increased; while, after 30 days, 13-HOD, 13-HPOT, 9-HPOD, 9-HPOT, 9-HOT, 9-KOT increased and 13-KOT, 9-KOD and JA decreased.
As oxylipins can be formed either enzymatically or not, the enantiomeric composition analysis allowed us distinguishing between the two mechanisms. A high $S$ percentage (>80\%) is typical for enzymatic mechanism while an increased proportion of $R$ form indicates an auto-oxidation phenomenon. Due to analytical restrictions, only the more abundant oxylipins can be collected and analyze on chiral phase HPLC column to determine the $R / S$ ratio. As revealed in Table 2, 13-HOD, 13-HOT, 13-HPOD, 13-HPOT, 9-HPOD, 9-HPOT, 9-HOD, 9-HOT were all of enzymatic origin in roots of both stressed and non-stressed plants for all kinetic points. In leaves, 13HOD, 13-HOT, 13-HPOT, 9-HPOD, 9-HPOT, 9-HOD, 9-HOT were also formed enzymatically in all conditions, while 13-HPOD with its low $S / R$ ratio was clearly synthesized by auto-oxidation.

\section{Gene expression}

Gene expression of both the main lipoxygenase isoforms and main enzymes of the lipoxygenase pathway was quantified using macro-array membranes. As a positive control, three classes of genes usually reported to be up-regulated under salt-stress conditions were included in the study (dehy, aqu and lea). Quantification was performed on two independent biological assays and the average value is presented in Table 3 . It is generally assumed that a significant modification is observed when an increase or decrease of a factor at least of two is measured. It can be noted from Table 3 that neither lipoxygenase genes nor fatty acid hydroperoxide decomposing enzymes correspond to this criterion in either roots or leaves. dehy, aqu and lea gene expression revealed a contrasting difference between roots and leaves. In leaves, no significant up or down-regulation of gene could be observed while in roots, a clear increase was observed after 5 days of salt stress for dehy2, aqu2, lea4 and lea5. The increase was observed after 21 days for dehy3 and aqu1. Thirty days after salinization, dehy3, aqu1, aqu2, lea4 gene were still significantly overexpressed. The aqu2 gene demonstrated, under our experimental conditions, the earliest and the strongest response to salt stress in tomato roots.

\section{Discussion}

A specific organ-dependent (root vs. leaves) oxylipin signature could be observed under salt stress conditions in tomato

It has been shown previously that LOX activity and lipid peroxidation (MDA content) increase in tomato cell suspension cultures adapted to salt stress by successive subcultures (Molina et al., 
ROOTS

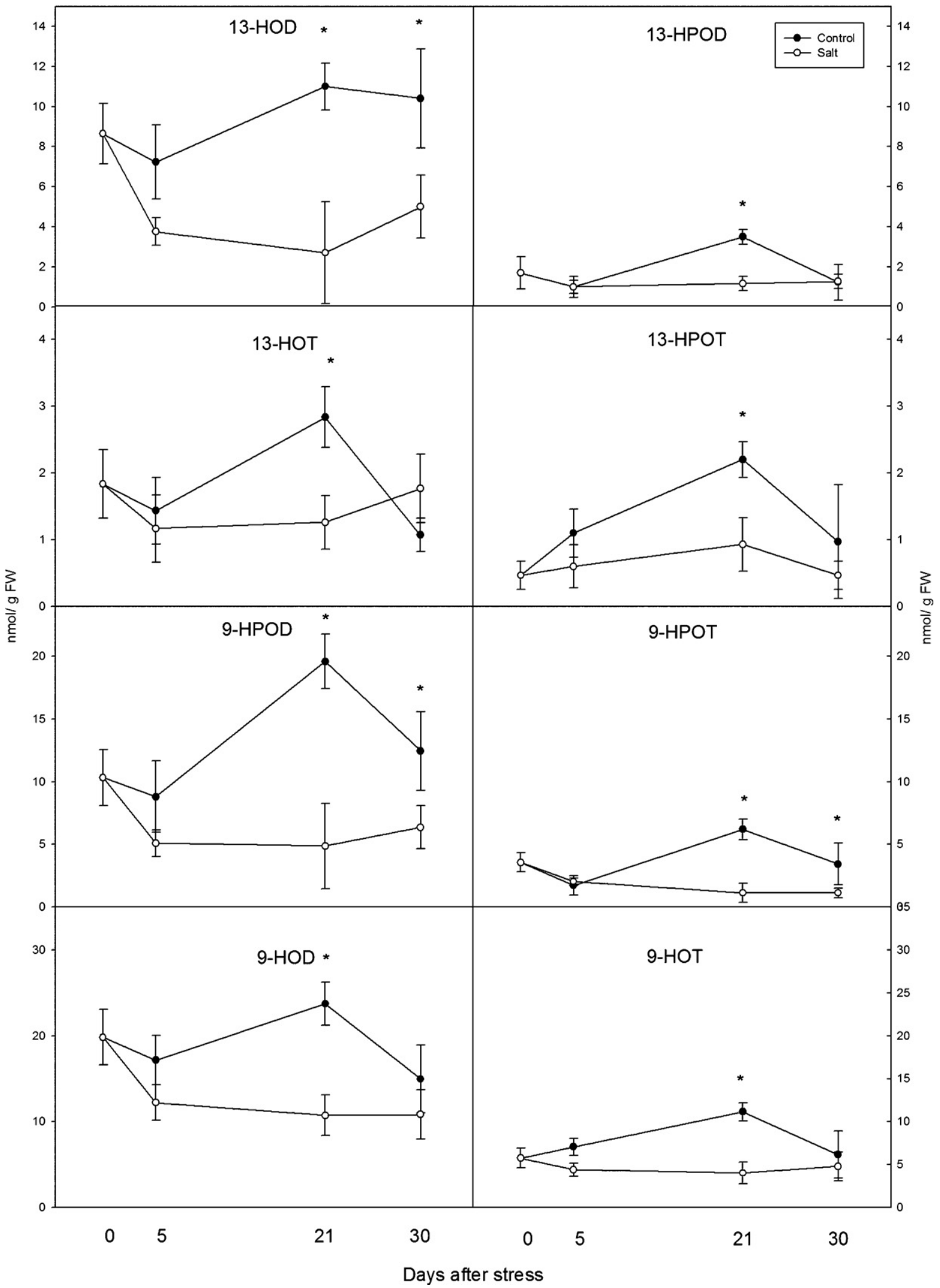

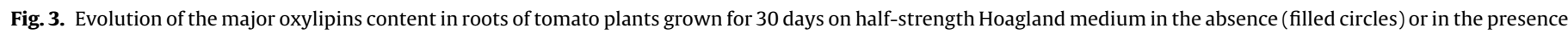

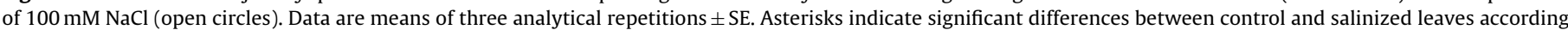
to Student-Newman-Keuls test at $P<0.05$. 
ROOTS

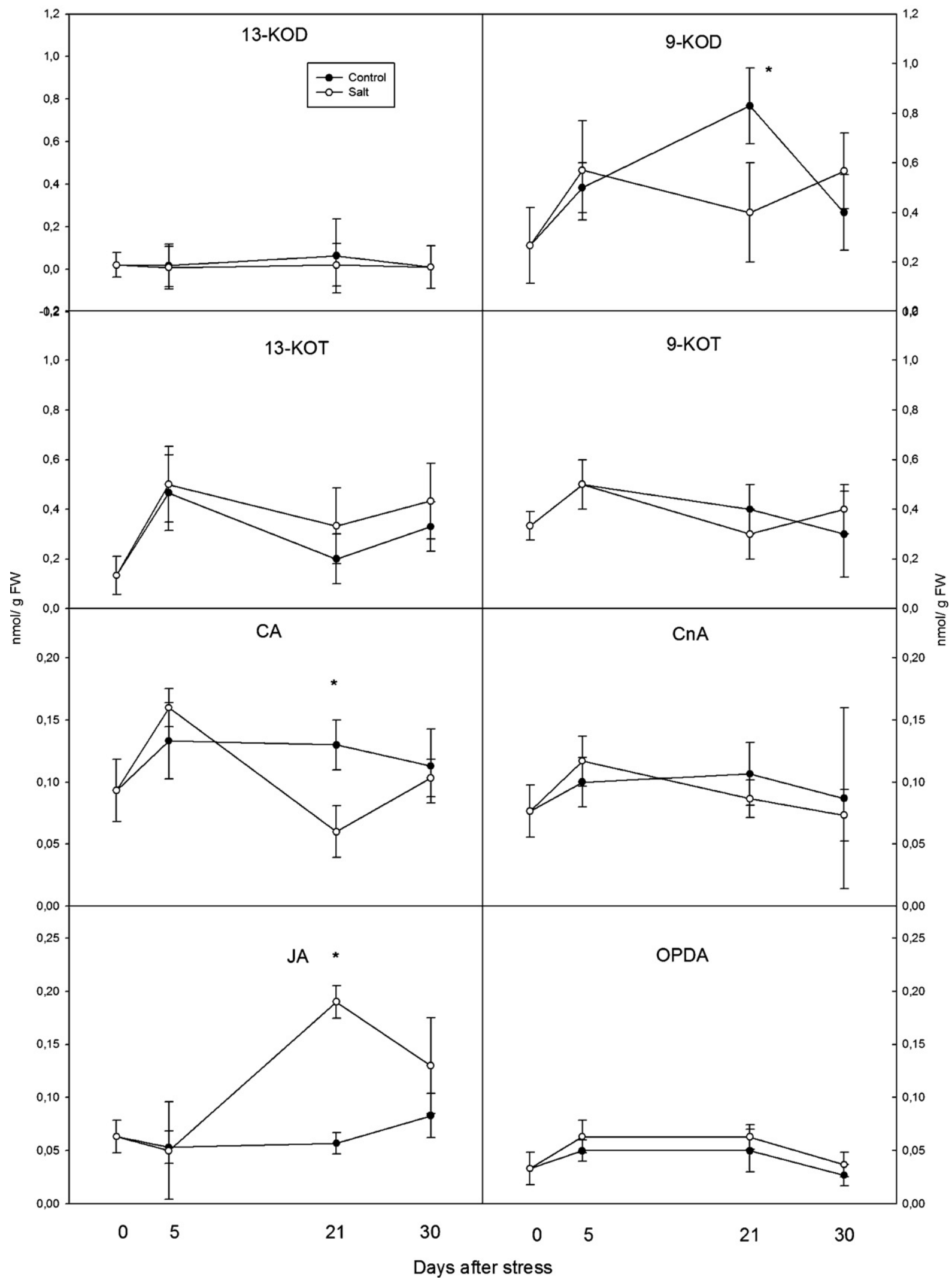

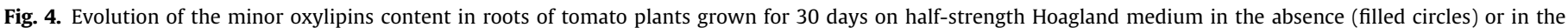

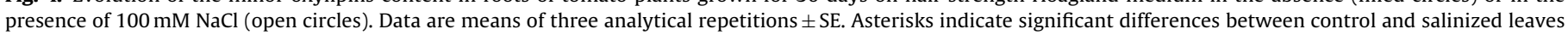
according to Student-Newman-Keuls test at $P<0.05$. 


\section{LEAVES}

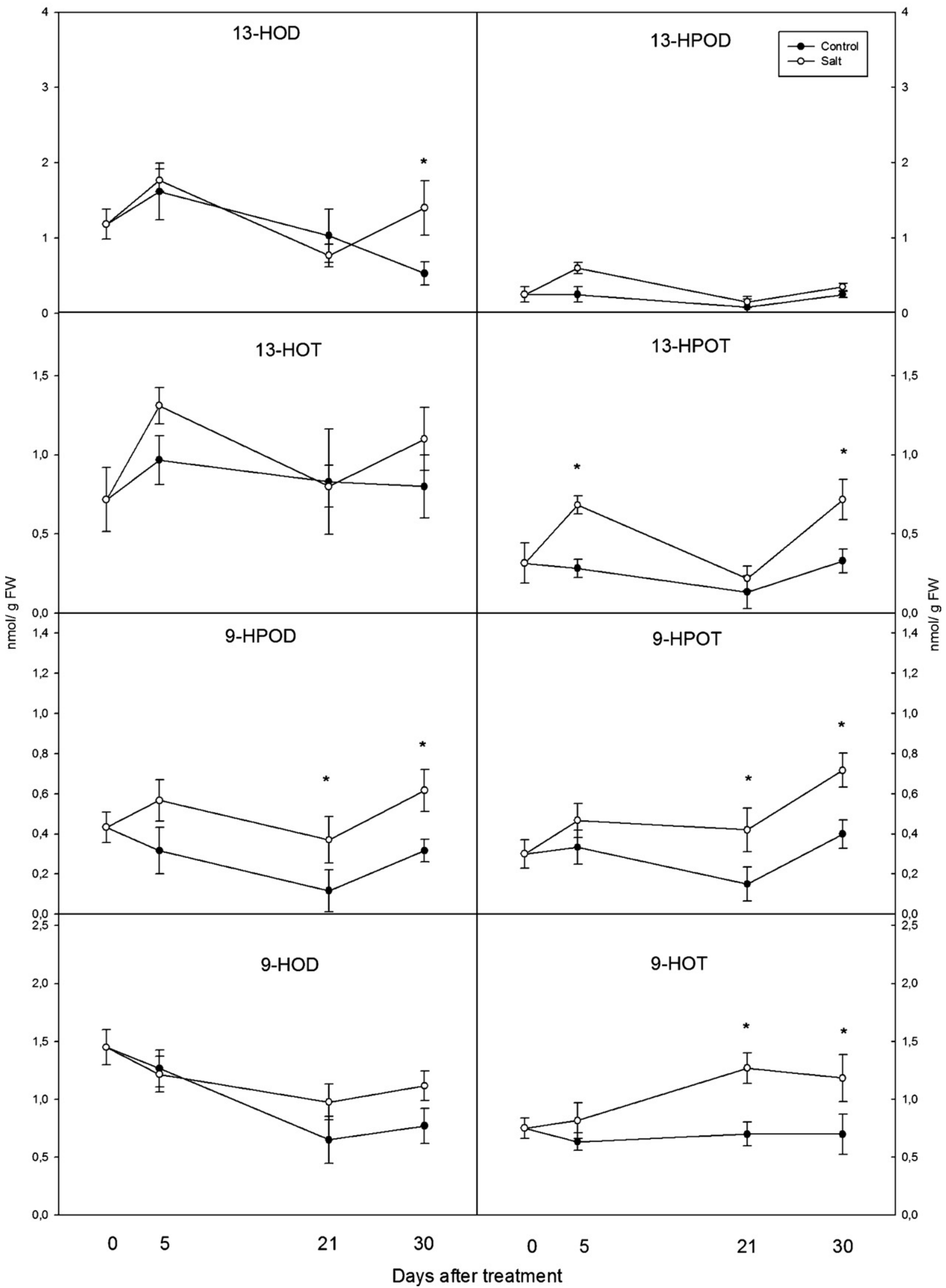

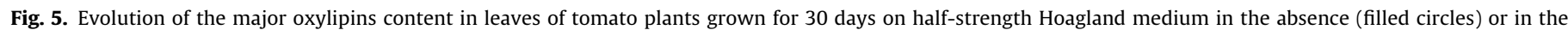

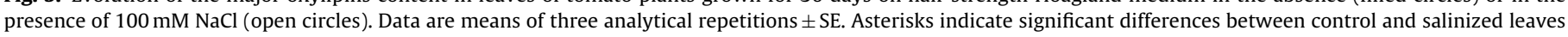
according to Student-Newman-Keuls test at $P<0.05$. 


\section{LEAVES}

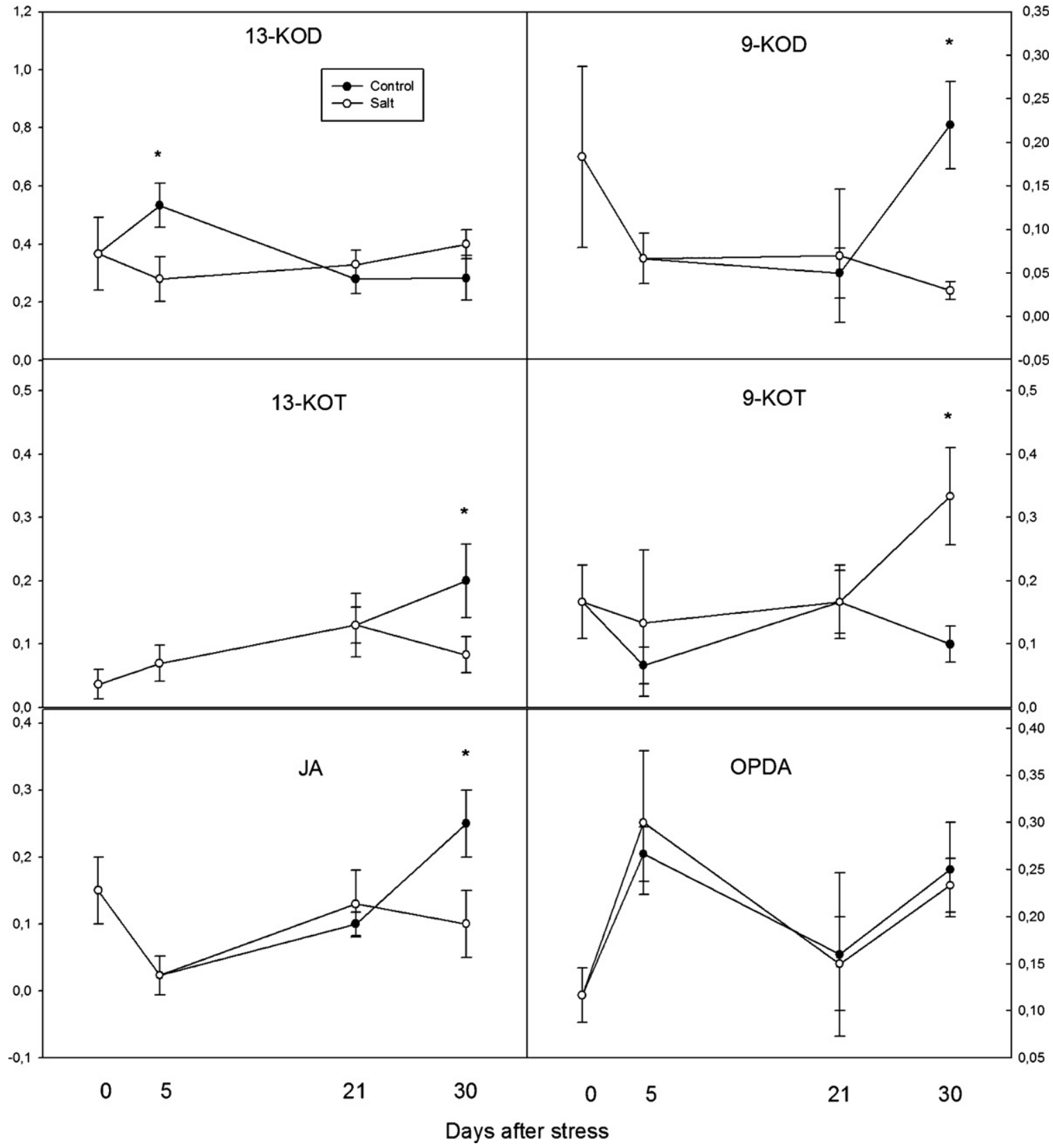

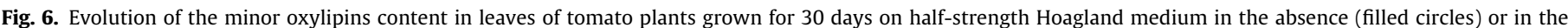

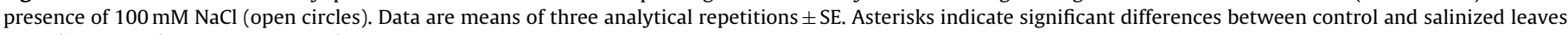
according to Student-Newman-Keuls test at $P<0.05$.

2002). An increase in lipid peroxidation was also observed in Catharanthus roseus suspension cells after salt treatment (Elkahoui et al., 2005), while a particular isoform of LOX was induced in Citrus sinensis tolerant cells after salinization (Ben-Hayyim et al., 2001). In a previous preliminary work, we explored oxylipin concentrations and LOX pathway in young tomato seedlings (8 days old) subjected to salt stress for 4 days (Delaplace et al., 2009). An increase in LOX activity was observed without any oxylipin accumulation which led us to extend the investigations.

The present study revealed a contrasted organ-dependent oxylipin signature in response to salt stress in tomato plants. Indeed, as far as roots were concerned, 11 oxylipins out of the 14 analyzed decreased significantly 21 days after salinization (13HOD/T, 13-HPOD/T, 9-HPOD/T, 9-HOD/T, 13-9-KOD, and CA), while this remained the case for only three of them 30 days after salinization (13-HOD, 9-HPOD/T). In leaves, three oxylipin concentrations increased after 21 days of salt stress application (9-HPOD/T and 9HOT), and six after 30 days (13-HOD, 13-HPOT, 9-HPOD/T, 9-HOT, 9-KOT).

In agreement with the previously reported increase in MDA in salinized tomato leaves by Ghanem et al. (2008), a significant increase in concentrations of its precursor 13-HPOT (and its corresponding reduced form 13-HOT) was observed at day 5 in the leaves of salinized tomato plants; 13 -HPOT was the only oxylipin that significantly accumulated at day 5 of salt treatment. This last result reveals the importance of assessing lipid peroxidation as a whole and not only focusing on a particular metabolite (Göbel and Feussner, 2009). 
Table 2

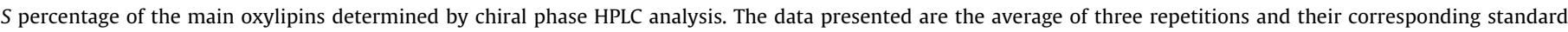
deviations.

\begin{tabular}{|c|c|c|c|c|c|c|c|}
\hline Compounds & $\begin{array}{l}\text { Roots } \\
\text { Day } 0\end{array}$ & $\begin{array}{l}\text { Roots } \\
\text { Day } 5 \\
\text { Control }\end{array}$ & $\begin{array}{l}\text { Roots } \\
\text { Day } 5 \\
\mathrm{NaCl}\end{array}$ & $\begin{array}{l}\text { Roots } \\
\text { Day } 21 \\
\text { Control }\end{array}$ & $\begin{array}{l}\text { Roots } \\
\text { Day } 21 \\
\mathrm{NaCl}\end{array}$ & $\begin{array}{l}\text { Roots } \\
\text { Day } 30 \\
\text { Control }\end{array}$ & $\begin{array}{l}\text { Roots } \\
\text { Day } 30 \\
\mathrm{NaCl}\end{array}$ \\
\hline 13-HOD & $94 \pm 5$ & $97 \pm 5$ & $90 \pm 6$ & $90 \pm 4$ & $89 \pm 7$ & $91 \pm 6$ & $91 \pm 7$ \\
\hline 13-HOT & $90 \pm 4$ & $88 \pm 5$ & $89 \pm 5$ & $91 \pm 5$ & $96 \pm 5$ & $94 \pm 5$ & $90 \pm 5$ \\
\hline 13-HPOD & $90 \pm 6$ & $94 \pm 6$ & $91 \pm 7$ & $91 \pm 6$ & $89 \pm 6$ & $88 \pm 4$ & $94 \pm 6$ \\
\hline 13-НРOT & $91 \pm 5$ & $91 \pm 4$ & $94 \pm 6$ & $94 \pm 7$ & $90 \pm 3$ & $91 \pm 6$ & $90 \pm 10$ \\
\hline 9-HPOD & $89 \pm 5$ & $88 \pm 5$ & $98 \pm 4$ & $92 \pm 6$ & $92 \pm 7$ & $89 \pm 5$ & $93 \pm 7$ \\
\hline 9-НРОТ & $92 \pm 4$ & $98 \pm 5$ & $86 \pm 5$ & $93 \pm 5$ & $94 \pm 4$ & $90 \pm 5$ & $96 \pm 8$ \\
\hline 9-HOD & $96 \pm 6$ & $94 \pm 8$ & $87 \pm 6$ & $88 \pm 9$ & $93 \pm 5$ & $88 \pm 6$ & $89 \pm 5$ \\
\hline 9-HOT & $92 \pm 7$ & $93 \pm 5$ & $96 \pm 5$ & $91 \pm 5$ & $89 \pm 5$ & $96 \pm 7$ & $92 \pm 7$ \\
\hline \multirow[t]{3}{*}{ Compounds } & Leaves & Leaves & Leaves & Leaves & Leaves & Leaves & Leaves \\
\hline & Day 0 & Day 5 & Day 5 & Day 21 & Day 21 & Day 30 & Day 30 \\
\hline & & Control & $\mathrm{NaCl}$ & Control & $\mathrm{NaCl}$ & Control & $\mathrm{NaCl}$ \\
\hline 13-HOD & $90 \pm 4$ & $94 \pm 5$ & $86 \pm 5$ & $94 \pm 4$ & $90 \pm 4$ & $92 \pm 8$ & $87 \pm 6$ \\
\hline 13-НОТ & $88 \pm 5$ & $96 \pm 3$ & $95 \pm 4$ & $96 \pm 4$ & $89 \pm 5$ & $84 \pm 4$ & $91 \pm 7$ \\
\hline 13-HPOD & $62 \pm 4$ & $65 \pm 5$ & $60 \pm 5$ & $49 \pm 5$ & $56 \pm 6$ & $66 \pm 6$ & $61 \pm 4$ \\
\hline 13-НPOT & $87 \pm 4$ & $93 \pm 5$ & $95 \pm 5$ & $93 \pm 4$ & $94 \pm 4$ & $94 \pm 7$ & $94 \pm 4$ \\
\hline 9-HPOD & $94 \pm 4$ & $89 \pm 3$ & $88 \pm 6$ & $88 \pm 6$ & $92 \pm 4$ & $86 \pm 5$ & $94 \pm 4$ \\
\hline 9-НРОТ & $90 \pm 4$ & $92 \pm 4$ & $97 \pm 5$ & $98 \pm 7$ & $94 \pm 4$ & $93 \pm 6$ & $89 \pm 7$ \\
\hline 9-HOD & $94 \pm 3$ & $94 \pm 4$ & $94 \pm 4$ & $84 \pm 6$ & $94 \pm 4$ & $96 \pm 6$ & $91 \pm 5$ \\
\hline 9-HOT & $85 \pm 5$ & $94 \pm 4$ & $89 \pm 4$ & $87 \pm 6$ & $98 \pm 6$ & $93 \pm 4$ & $93 \pm 7$ \\
\hline
\end{tabular}

In roots, oxylipins that decreased after salinization belong both to the 13- and 9-LOX pathways. The phenomenon cannot thus be attributed to the regulation of a particular LOX isoform (e.g. LOX A is a 9-LOX and LOX D is a 13-LOX, Andreou and Feussner, 2009), as is the case in the Ben-Hayyim et al. (2001) study. In leaves, the oxylipins that accumulated in salinized plants also belonged to the two pathways. When comparing oxylipin profiles and LOX gene expression patterns, no clear correlation could be established between the two, despite the fact that there were some tendencies observed. Among oxylipins, some of the compounds are end products such as $\mathrm{HOD} / \mathrm{T}, \mathrm{KOD} / \mathrm{T}$ and $\mathrm{Cn} \mathrm{A}$, while HPOT/D is an intermediate compound that can be further transformed into other oxylipins or esterified to complex lipids, therefore making the establishment of a clear correlation between metabolite concentrations and the related gene expression difficult. As mentioned before, only a decrease or increase by a factor of two in gene expression levels is commonly considered as a significant change. Nevertheless, the data can be interpreted, with prudence, in terms of tendency. In leaves, three of the four LOX isoforms measured (Lox A, Lox B and
Lox E) tended to increase (day 30) while all of them (Lox A, Lox B, Lox D and Lox E) tended to decrease in roots (day 30 ), which is consistent with the respective oxylipin organ-dependent increase or decrease upon salt stress application.

When regarding, more particularly, the LOX pathway phytohormones, it has been shown that jasmonic acid and its precursor accumulate in tomato hairy roots culture after salt stress application (Abdala et al., 2003). The same phenomenon was observed in tomato plants in the hours following salt stress application, to a higher extent in salt-tolerant cultivars (Pedranzani et al., 2003).

In our study, JA content increased significantly in roots 21 days after salinization, while its precursor OPDA remained unchanged. In leaves, JA decreased significantly at day 30 of salt stress, and OPDA content was not modified.

JA results from a cascade of enzymatic reactions in the following order: LOX-AOS-AOC-several oxo-phytodienoate reductases (Oprs). AOS and AOC gene expression exhibited a tendency to increase both in leaves and roots, while the evolution of Opr is not clear. Free JA is a key intermediate leading to the volatile methyl

Table 3

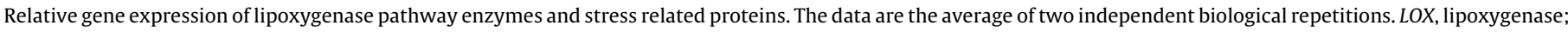

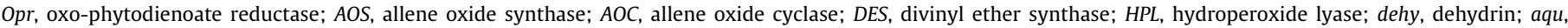
aquaporin; lea, late embryogenesis abundant.

\begin{tabular}{|c|c|c|c|c|c|c|}
\hline & $\begin{array}{l}\text { Leaves } 5 \text { days } \\
\text { stressed/control }\end{array}$ & $\begin{array}{l}\text { Leaves } 21 \text { days } \\
\text { stressed/control }\end{array}$ & $\begin{array}{l}\text { Leaves } 30 \text { days } \\
\text { stressed/control }\end{array}$ & $\begin{array}{l}\text { Roots } 5 \text { days } \\
\text { stressed/control }\end{array}$ & $\begin{array}{l}\text { Roots } 21 \text { days } \\
\text { stressed/control }\end{array}$ & $\begin{array}{l}\text { Roots } 30 \text { days } \\
\text { stressed/control }\end{array}$ \\
\hline Lox A & 1.49 & 1.34 & 1.48 & 1.45 & 1.49 & 0.6 \\
\hline Lox $B$ & 0.93 & 1.00 & 1.09 & 1.30 & 0.97 & 0.78 \\
\hline Lox $D$ & 1.48 & 1.16 & 0.77 & 1.34 & 1.81 & 0.70 \\
\hline Lox $E$ & 0.94 & 0.79 & 1.30 & 0.71 & 1.45 & 0.70 \\
\hline Opr1 & 1.02 & 0.70 & 0.93 & 1.10 & 1.15 & 0.71 \\
\hline Opr2 & 0.80 & 1.53 & 1.38 & 0.65 & 0.78 & 0.67 \\
\hline Opr3 & 1.51 & 1.16 & 0.67 & 1.52 & 0.89 & 0.99 \\
\hline$A O S$ & 0.86 & 1.73 & 1.48 & 1.13 & 1.54 & 1.28 \\
\hline AOC10 & 0.77 & 1.40 & 1.17 & 1.29 & 1.32 & 1.33 \\
\hline DES & 1.19 & 1.35 & 1.29 & 1.68 & 0.79 & 0.67 \\
\hline HPL & 1.24 & 1.37 & 1.17 & 1.15 & 1.32 & 1.09 \\
\hline dehy1 & 1.14 & 1.4 & 1.29 & 0.61 & 1.33 & 0.89 \\
\hline dehy2 & 1.09 & 0.73 & 1.49 & 2.04 & 3.49 & 1.48 \\
\hline dehy3 & 0.79 & 0.71 & 1.13 & 1.93 & 5.06 & 3.49 \\
\hline aqu1 & 0.66 & 1.39 & 1.87 & 1.47 & 4.04 & 2.80 \\
\hline aqu2 & 1.12 & 0.83 & 1.02 & 3.47 & 4.24 & 6.76 \\
\hline lea4 & 0.76 & 1.61 & 0.85 & 3.49 & 1.80 & 4.37 \\
\hline lea5 & 1.46 & 0.73 & 1.28 & 2.13 & 4.86 & 0.75 \\
\hline
\end{tabular}


JA, or different forms conjugated to sugars or amino acids or esterified in complex lipids. Interpretation of the role of JA is thus not simple: methyl JA, free JA, conjugated and esterified forms can all exhibit biological activities, while conjugated and esterified forms can also be a storage form allowing the release of the free form in stress contexts (Browse, 2009; Mueller et al., 2008). Our results are compatible with a signaling role for JA in salt stress, but further experiments are required to strengthen this hypothesis. It has been shown that various oxylipins, in addition to jasmonates, can be found in the phloem revealing a potential signaling role (Harmel et al., 2007). Nevertheless, the difference between the signature of root and leaf oxylipins under salt stress does not support the hypothesis of a translocation via the phloem sap.

\section{Changes in oxylipin signature differ between early and later stage of salt stress response in tomato}

From a kinetic point of view, it is generally assumed that salt stress can be decomposed in two distinct phases: the first one, called the osmotic effect, is due to the reduction of plant capacity to take up water. The second phase of the growth response (the ionic phase) results from the toxic effect of salt inside the plant. If excessive amounts of $\mathrm{Na}^{+}$or $\mathrm{Cl}^{-}$enter the plant, they may rise to toxic levels in the older transpiring leaves, causing premature death of leaves (Munns, 2005). Salinity reduces plant productivity firstly by reducing plant growth during the osmotic stress phase, and secondly by inducing leaf senescence during the toxicity phase when excessive salt is accumulated in transpiring leaves (Munns, 2002).

Following the imposition of salinity, shoot growth arrest usually occurs very quickly (within seconds to minutes) but recovers (over several hours) to lead to a new steady state that can be considerably lower than under non-stress conditions, thus inhibiting cell expansion and cell division and promoting stomatal closure for the duration of exposure to salinity (Munns, 2005; Pérez-Alfocea et al., 2010).

As almost no modification in oxylipin pattern could be observed at day 5 in either roots or leaves, it can be concluded that the organdependent oxylipin signature is mainly associated with the latest phase of salt stress in which the ionic effect predominates. It can also be noted that the oxylipin profile modification appeared first in roots (day 21), and then in leaves (day 30). Hence, other processes or endogenous factors than those occurring in the first days of salinization, when the osmotic effect predominated, were probably influencing the evolution of leaf senescence and root growth. The capacity of the plant to regulate the accumulation of toxic ions may thus noticeably influence the stress-induced changes in oxylipin signature.

\section{Main oxylipins seem to be formed enzymatically through the LOX pathway}

As revealed by physiological observations $\left(F_{\mathrm{v}} / F_{\mathrm{m}}\right)$, leaf senescence was physiologically observed at day 21 after salt stress application. Up-regulation of dehy, aqu and lea gene expression in salt-stressed plants, when compared to the control, confirmed that exogenous $\mathrm{NaCl}$ application induced a physiological constraint in stressed plants. Indeed, late embryogenis abundant proteins can accumulate under salt stress conditions, contributing to protect proteins and the membrane during periods of water deficit (Hand et al., 2011); dehydrin is a particular group of late embryogenis abundant proteins (Kosova et al., 2007). Aquaporins are involved in the regulation of water movement through the membranes and contribute to reduce cellular osmotic stress (Martinez-Ballestra et al., 2006).
Our study reveals that in roots, a significant decrease in several oxylipin concentrations was initiated at day 5 , and that such a decrease was reinforced at day 21 after salt treatment. Moreover, the enantiomeric characterization of oxylipins revealed that they are all formed enzymatically. This indicates that no massive autooxidation of lipids occurred in the organs that were in direct contact with salt and that membranes were thus probably not subjected to a strong peroxidation process. In leaves where physiological damage can be clearly established, slight increases in oxylipin content were observed in salt-stressed plants, and all oxylipins (except 13HPOD) were formed enzymatically, as revealed by their high $S / R$ ratios. In the context of abscission, where leaves also undergo a senescence process, a drastic increase in oxylipin concentrations of auto-oxidation origin has been demonstrated (Berger et al., 2001). Such a non-enzymatic oxidation process was clearly not observed, here, in the salt stress context.

The role of JA in natural senescence is not as clear, given that divergent results have been published to date. An accumulation of free JA and OPDA occurred in natural and induced-senescence in Arabidopsis leaves, while modification of the esterified JA form, was not systematic (Seltmann et al., 2010). In our study, no OPDA or JA accumulation could be observed in salt-induced senescing leaves.

\section{Concluding remarks}

Numerous studies on salt stress in plants have revealed the complexity of the response to this abiotic stress, including the distinct response to the osmotic and ionic components, the various molecules involved in the signalization, and also the multigenic nature of the response.

As has been demonstrated before for other (a)biotic stresses, we have shown in this study that clear organ-dependent oxylipin signatures are generated in roots and leaves under salt-stress conditions. The modifications appear in the late phase of plant response, first in the roots, then in the leaves. As oxylipins are formed enzymatically, and as their contents decrease in roots and accumulate only to a minor extent in leaves, it can be concluded that plants have developed efficient processes to avoid a massive peroxidation process that could potentially damage their membranes. Moreover, the leaf senescence observed under salt stress in tomato is not due to a massive lipid peroxidation. The potential role of the oxylipin phytohormones (JA) in salt stress is hypothesized, indicating that the LOX pathway is more important in signaling in salt stress response than in being a source of peroxidation.

\section{Acknowledgments}

The authors thank Adeline Blondiaux for efficient technical assistance with the oxylipin analysis, and Aurélie Gfeller for critical reading of this manuscript. Research was supported by the FNRS Belgium (convention $\mathrm{n}^{\circ} 2.4563 .08$ and 1.5.090.08), the Tobby and Gorda Foundation, the Fundación Séneca de la Región de Murcia (project 08712/PI/08) and Ministerio de Ciencia y Innovación (MICINN-FEDER, project AGL2008-01733/AGR), Spain. MEG is Chargé de Recherches of the Fonds de la Recherche Scientifique FRS-F.N.R.S. (Belgium).

\section{References}

Abdala G, Miersch O, Kramell R, Vigliocco A, Agostini E, Forchetti G, et al. Jasmonate and octadecanoic occurrence in tomato hairy roots. Endogenous level changes in response to $\mathrm{NaCl}$. Plant Growth Regul 2003;40:21-7.

Albacete A, Ghanem ME, Martinez-Andujar C, Acosta M, Sanchez-Bravo J, Martinez $\mathrm{V}$, et al. Hormonal changes in relation to biomass partitioning and shoo growth impairment in salinised tomato (Solanum lycopersicum L.) plants. J Exp Bot 2008;59:4119-31.

Albacete A, Martinez-Andujar C, Ghanem ME, Acosta M, Sanchez-Bravo J, Asins $\mathrm{MJ}$, et al. Rootstock-mediated changes in xylem ionic and hormonal status are 
correlated with delayed leaf senescence and increased leaf area and crop productivity in salinised tomato. Plant Cell Environ 2009;32:928-38.

Andreou A, Feussner I. Lipoxygenases - structure and reaction mechanism. Phytochemistry 2009;70:1504-10.

Ben-Hayyim G, Gueta-Dahan Y, Avsian-Kretchmer O, Weichert H, Feussner I. Preferential induction of a 9-lipoxygenase by salt-tolerant cells of Citrus sinensis $\mathrm{L}$. Osbeck. Planta 2001;212:367-75.

Berger S, Weichert H, Porzel A, Wasteranck C, Kühn H, Feussner I. Enzymatic and non-enzymatic lipid peroxidation in leaf development. Biochim Biophys Acta 2001;1533:266-79.

Blée E. Impact of phyto-oxylipins in plant defense. Trend Plant Sci 2002;7:315-23.

Browse J. Jasmonate passes muster: a receptor and targets for the defense hormone. Annu Rev Plant Biol 2009;60:183-205.

Delaplace P, Frettinger P, Ghanem ME, Blondiaux A, Bauwens J, Cotton S, et al Lipoxygenase pathway and antioxidant system in salt stressed tomato seedlings (Lycopersicon esculentum Mill.). Biotechnol Agron Soc Environ 2009;13:529-36.

Elkahoui S, Hernadez JA, Abdelly C, Ghrir R, Limam F. Effects of salt on lipid peroxidation and antioxidant enzyme activities of Catharanthus roseus suspension cells. Plant Sci 2005;168:607-13.

Fauconnier M-L, Rojas-Beltran J, Dupuis B, Delaplace P, Frettinger P, Gosset V, et al. Changes in oxylipin synthesis after Phytophthora infestans infection of potato leaves do not correlate with resistance level. Plant Phys Biochem 2008;46:823-31.

Ghanem ME, Albacete A, Martinez-Andujar C, Acosta M, Romero-Aranda R, Dodd IC, et al. Hormonal changes during salinity-induced leaf senescence in tomato (Solanum lycopersicum L.). J Exp Bot 2008;59:3039-50.

Ghanem ME, Hichri I, Smigocki AC, Albacete A, Fauconnier ML, Diatloff E, et al. Roottargeted biotechnology to mediate hormonal signalling and improve crop stress tolerance. Plant Cell Rep 2011;30:807-23.

Göbel C, Feussner I. Methods for the analysis of oxylipins in plants. Phytochemistry 2009;70:1485-503.

Göbel C, Feussner I, Hamberg M, Rosahl S. Oxylipin profiling in pathogen infected potato leaves. Biochim Biophys Acta 2002;1584:55-64.

Gosset V, Nicolas H, Cornelia G, Francis F, Haubruge E, Wathelet JP, et al. Attacks by a piercing-sucking insect (Myzus persicae Sultzer) or a chewing insect (Lep tinotarsa decemlineata Say) on potato plants (Solanum tuberosum L.) induce differential changes in volatile compound release and oxylipin synthesis. J Exp Bot 2009;60:1231-40.

Hand CH, Menze MA, Toner M, Boswell L, Moore D. LEA proteins during water stress: not just for plants anymore. Annu Rev Physiol 2011;73:115-34.

Harmel N, Delaplace P, Blée E, Haubruge E, du Jardin P, Fauconnier M-L. Myzus persicae Sulzer aphid contains oxylipins that originate from phloem sap. J Plant Interact 2007;2:31-40.
Kosova K, Vitamvas P, Prasil IT. The role of dehydrins in plant response to cold. Biol Plantarum 2007;51:601-17.

Martinez-Ballestra MC, Silva C, Lopez-Berenguer CL, Cabanero FJ, Carjaval M. Plant aquaporins: new perspectives on water and nutrient uptake in saline environment. Plant Biol 2006;8:535-46.

Molina A, Bueno P, Marin MC, Rodriguez-Rosales M, Belver A, Venema K, et al. Involvement of endogenous salicylic acid content lipoxygenase and antioxidant enzyme activities in the response of tomato cell suspension cultures to $\mathrm{NaCl}$. New Phytol 2002;156:409-15.

Mosblech A, Feussner I, Heilmann I. Oxylipins: structurally diverse metabolites from fatty acid oxidation. Plant Phys Biochem 2009;47:511-7.

Mosblech A, Feussner I, Heilmann I. Oxylipin signaling and plant growth. In: Munnik T, editor. Lipid signaling in plants. Berlin: Springer-Verlag; 2010. p. 277-91.

Mueller S, Hilbert B, Dueckershoff K, Roitsch T, Krischke M, Mueller MJ, et al. General detoxification and stress responses are mediated by oxidized lipids through TGA transcription factors in Arabidopsis. Plant Cell 2008;20:768-85.

Munns R. Salinity, growth and phytohormones. In: Lâuchli A, Lüttge U, editors. Salinity: environment-plants-molecules. New York: Kluwer Academic Publishers; 2002. p. 271-90.

Munns R. Genes and salt tolerance: bringing them together. New Phytol 2005;167:645-63.

Munns R. Plant adaptations to salt and water stress: differences and commonalities. Adv Bot Res 2011;57:1-32.

Munns R, Tester M. Mechanisms of salinity tolerance. Annu Rev Plant Biol 2008;59:651-81.

Pedranzani H, Racagni G, Alemano S, Miersch O, Ramirez I, Pena-Cortes H, et al. Salt tolerant tomato plants show increased levels of jasmonic acid. Plant Growth Regul 2003;41:149-58.

- Pérez-Alfocea F, Albacete A, Ghanem ME, Dodd IC. Hormonal regulation of source-sink relations to maintain crop productivity under salinity: a case study of root-to-shoot signalling in tomato. Funct Plant Biol 2010;37:592-603.

Qadir M, Oster JD, Schubert S, Noble AD, Sahrawat KL. Phytoremediation of sodic and saline-sodic soils. Adv Agron 2007;96:197-247.

Sambrook J, Russell DW. The condensed protocols: from molecular cloning: a laboratory manual. New York, USA: CSHL Press; 2006.

Seltmann MA, Stingl NE, Lautenschlaeger JK, Krischke M, Mueller M, Berger S. Differential impact of lipoxygenase 2 and jasmonates on natural and stress-induced senescence in Arabidopsis. Plant Physiol 2010;152:1940-50.

Wang SX, Hunter W, Plant A. Isolation and purification of functional total RNA from woody branches and needles of Sitka and white spruce. Biotechniques 2000;28:292-6.

Zhu JK. Plant salt tolerance. Trends Plant Sci 2001;6:66-71. 